\title{
Sex Differences in Aging of the Human Frontal and Temporal Lobes
}

\author{
Patricia E. Cowell, ${ }^{1}$ Bruce I. Turetsky, ${ }^{1}$ Ruben C. Gur, ${ }^{1}$ Robert I. Grossman, ${ }^{2}$ Derri L. Shtasel,, and \\ Raquel E. Gur ${ }^{1}$ \\ Departments of 'Psychiatry and ${ }^{2}$ Radiology, University of Pennsylvania, Philadelphia, Pennsylvania 19104
}

\begin{abstract}
This study investigated effects of age and sex on regional brain structure in humans, focusing on the frontal and temporal lobes. Hemispheric volumes were obtained from magnetic resonance images (MRIs) of 96 young (53 men, 43 women; aged 18-40 years) and 34 older (17 men, 17 women; aged 41-80) healthy volunteers. Images (5 $\mathrm{mm}$ axial spinecho, repetition time of $3000 \mathrm{msec}$ and echo times of 30 and $80 \mathrm{msec}$ ) were resliced along the anterior commissure-posterior commissure (AC-PC) axis to standardize for differences in head tilt, and imported into a computer program where borders of the frontal and temporal lobes were delineated. The program calculated regional brain volumes based on slice data from which CSF was segmented out. An age $x \operatorname{sex} \times$ hemisphere $x$ region interaction indicated that agerelated reductions in brain volume were sexually dimorphic, lateralized, and region specific. Greater decrements in brain volume occurred with age in the frontal lobe than in the temporal lobe. Age-related reductions in both regions were greater in men than in women, demonstrating that sexual dimorphisms in human neuroanatomy are not fixed, but continue to change throughout adulthood. The possibility that gonadal hormones play a role in the promotion and/or prevention of neural atrophy with aging is discussed.
\end{abstract}

[Key words: aging, sex differences, temporal lobe, trontal lobe, laterality, magnetic resonance imaging, human brain]

A growing body of literature suggests that age affects the sexes differently with regard to both brain structure (Hatazawa et al., 1982; Hubbard and Anderson, 1983; Laffey et al., 1984; Takeda and Matsuzawa, 1985; Grant et al., 1987; Condon et al., 1988; Allen et al., 1991; Gur et al., 1991) and physiological brain activity (Shaw et al., 1984; Gur et al., 1987; Rodriguez et al., 1988). At the level of whole-brain analysis in humans, findings have been mixed. The majority of studies found that the brains of men aged faster or earlier than those of women (Laffey et al., 1984; Takeda and Matsuzawa, 1985; Grant et al., 1987; Condon et al., 1988; Gur et al., 1991), whereas others reported the opposite effect (Hatazawa et al., 1982; Hubbard and Anderson, 1983; Allen et al., 1991). Yet, in many studies of aging, subjects were pooled across sex for some or all comparisons (Davis and Wright, 1977; Naritomi et al., 1979; Kuhl et al., 1982; Anderson

\footnotetext{
Received July 12, 1993; revised Nov. 2, 1993; accepted Jan. 13, 1994.

We thank Drs. Abass Alavi and Franz Payer for donating some of their subjects to this study. This work was supported by NIH Grants MH-42191, MH-19112, $\mathrm{MH}-43880, \mathrm{MH}-00586$, and 5-M01RR0040.

Correspondence should be addressed to Patricia E. Cowell, Brain Behavior Laboratory, 10 Gates Building/Hospital of the University of Pennsylvania, 36th and Spruce Streets, Philadelphia, PA 19104-42.83

Copyright (C) 1994 Society for Neuroscience $0270-6474 / 94 / 144748-08 \$ 05.00 / 0$
}

et al., 1983; Pantano el al., 1984; Terry et al., 1987; Jernigan et al., 1990; Leenders et al., 1990; Martin et al., 1991). Others used only one sex (Duara et al., 1984; Azari et al., 1992b) or did not mention sex (Buell and Coleman, 1979; Huttenlocher, 1979; de Leon et al., 1984).

The effects of age on neural structure have been widely reported from postmortem (Davis and Wright, 1977; Miller et al., 1980; Hubbard and Anderson, 1983), CT (Laffey et al., 1984; Takeda and Matsuzawa, 1985; Pfefferbaum et al., 1986), and MRI studies (Condon et al., 1988; Jernigan et al., 1990; Gur ct al., 1991). In general, advancing age has been associated with decreased brain tissue and increased CSF. Cytoarchitectural studies of aging found degenerative changes (Brody, 1955; Anderson et al., 1983; Terry et al., 1987) but also evidence for neural plasticity in the frontal and temporal lobes of older adults (Yakovlev and LeCours, 1967; Buell and Coleman, 1979). At the gross neuroanatomical level, Jack et al. (1992) reported decreased volume of the anterior temporal lobe and hippocampus. Coffey et al. (1992) found that both frontal and temporal volumes decreased with age, but that the frontal lobe exhibited a greater yearly decrement than the temporal lobe. These regional analyses suggest that structures within the frontal and temporal lobes are particularly sensitive to the effects of age. However, sex was examined only as a possible covariate of the aging process (Coffey et al., 1992; Jack et al., 1992).

Sex differences in the human brain have been demonstrated through cortical lesion effects (Kimura, 1986, 1987), functional imaging (Gur et al., 1982; Wood et al., 1990; Azari et al., 1992a) and brain-behavior correlations (Witelson, 1989, 1991; Kertesz et al., 1990; Zaidel et al., 1990; Denenberg et al., 1991). Sexually dimorphic neuroanatomy has also been the topic of many investigations over the past decade (deLacoste-Utamsing and Holloway, 1982; Demeter et al., 1988; Allen et al., 1989; Clarke et al., 1989; Allen and Gorski, 1990, 1991). Few have examined how sex differences in regional human neuroanatomy are influenced by age, despite increasing evidence from other species that many aspects of brain development (Toran-Allerand, 1978; MacLusky et al., 1979; Pomerantz et al., 1985; Fitch et al., 1990a,b, 199 la,b; Mack et al., 1993) and aging (Diamond et al., 1975, 1983; Brown et al., 1990; Fernandez-Ruiz et al., 1992) are influenced by gonadal steroids.

The purpose of the present study was to investigate the effects of age and sex on regional brain volume in a large, healthy population of subjects. We chose to examine dimorphisms in the frontal and temporal lobes, two regions shown to be sensitive to age.

\section{Materials and Methods}

Subjects. The sample included 130 healthy controls (70 men and 60 women) who responded to newspaper advertisements. Subjects ranged 


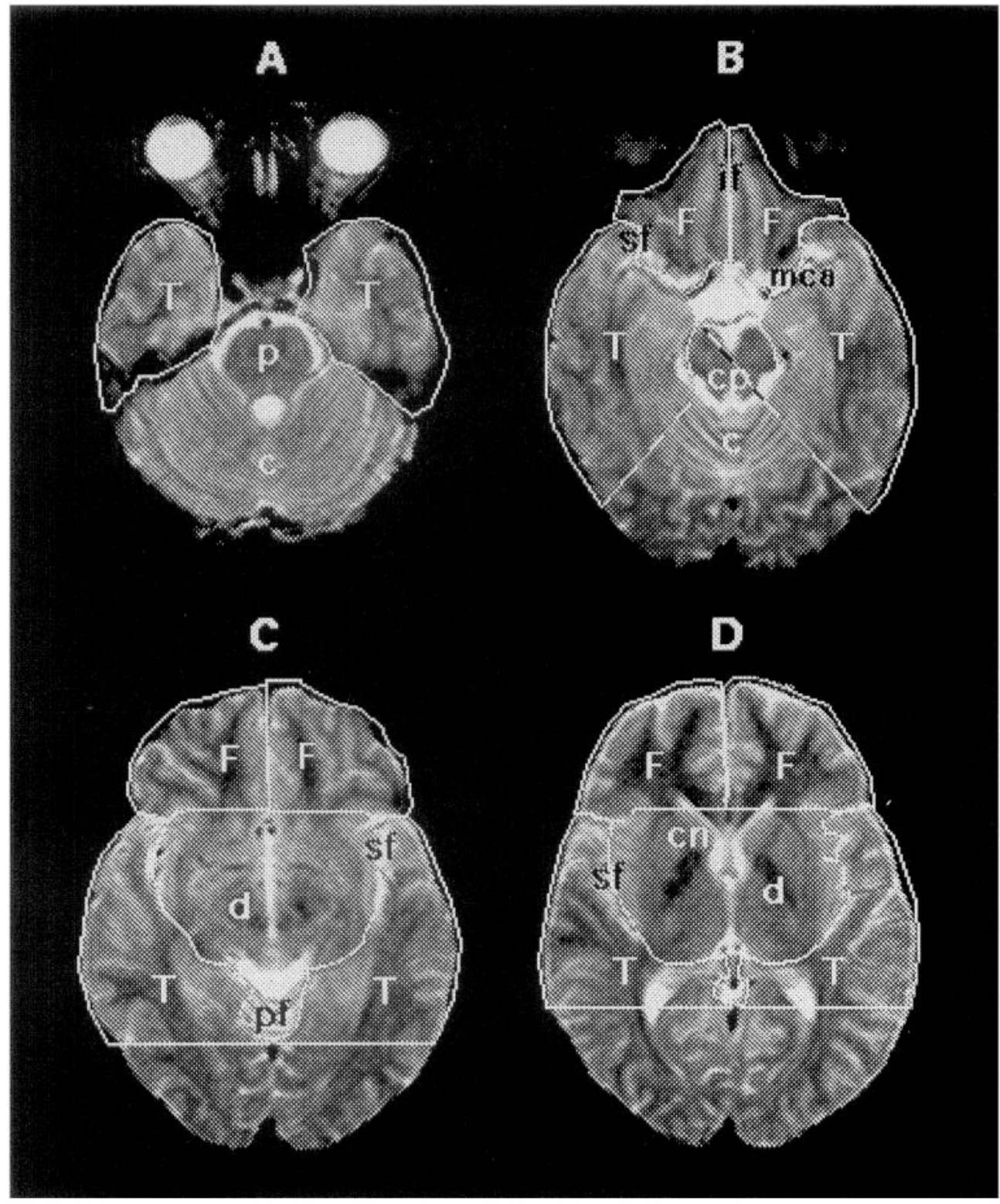

Figure 1. $A$, The temporal lobe region drawn onto a $5 \mathrm{~mm}$ axial $\mathrm{T} 2$ image. The region delineated is representative of temporal lobe drawings for all slices inferior to the one shown. $B$, The frontal and temporal lobe regions drawn on a slice located $1 \mathrm{~cm}$ superior to that shown in $A$. The line used to delineate the posterior temporal border is depicted with dashes from the anteriormost tip of the contralateral cerebral peduncle to the anteromedialmost tip of the cerebellum. The frontal and temporal lobe regions drawn onto slices located $1 \mathrm{~cm}$ and $2 \mathrm{~cm}$ superior to that shown in $B$ are depicted in $C$ and $D$, respectively. All frontal regions drawn on slices superior to the one shown in $D$ used the same posterior boundary. It should be noted that all regions drawn encompass tissue to be further segmented into brain and CSF volumes. $c$, cerebellum; $c n$, caudate nucleus; $c p$, cerebral peduncle; $F$, frontal region; $d$, diencephalon; if, interhemispheric fissure; $m c a$, middle cerebral artery; $p$, pons; $s f$, sylvian fissure; $T$, temporal region.

in age from 18 to 80 years (men: range $18-80$, mean $=34.74 \pm 2.12$ years; women: range $18-77$, mean $=34.65 \pm 2.32$ years). As part of standardized assessment procedures for normal subjects, participants underwent medical, neurologic, structured psychiatric and neuropsychological evaluations, and laboratory tests (Shtasel et al., 1991). The psychiatric evaluation included the Structured Clinical Interview for DSM-III-NP (nonpatient form; Spitzer et al., 1986). Participants had no history of current or previous disorders that could affect brain function such as hypertension, cardiac, pulmonary, renal, or endocrine disorders. In addition, none suffered from disorders of the CNS such as infection, seizure, head trauma with loss of consciousness, learning disability, alcohol or other substance abuse, or steroid use (estrogen replacement was an exclusionary criterion, use of birth control pills was not). There was no history of major psychiatric disorders in first-degree relatives. All subjects were right handed (Rackzowski et al., 1974). Informed consent was obtained before participation in the study.

MRI scanning. The MRIs were acquired on a 1.5 tesla scanner (GE Signa). Axial spin-echo images, $5 \mathrm{~mm}$ thick, were obtained using a repetition time (TR) of $3000 \mathrm{msec}$ and echo times (TE) of 30 and 80 msec in planes parallel to the canthomeatal axis with $5 \mathrm{~mm}$ spacing. Slices were interleaved so that there was no interslice gap.

Neuroradiologic evaluation of MRIs. Prior to regional measurement, brains were realigned in three dimensions using the software package
PETVIEW 1.1 and resliced along the AC-PC axis to standardize for differences in head tilt during image acquisition. Resliced images were then imported into another computer software package (Kohn et al., 1991) modified to accommodate regional analysis. The borders of the frontal and temporal lobes were drawn by investigators working with a neuroradiologist using standardized boundaries.

In the inferiormost slices, the temporal lobe did not share common lateral or anterior borders with other structures and was easily outlined. The posteromedial temporal lobe border was formed by the pons and cerebellum (Fig. 1A). At the level of the midbrain, borders of the frontal lobe were drawn along the interhemispheric fissure and followed the middle cerebral artery through the suprasellar cistern (Fig. 1B). The temporal lobe was separated from adjacent frontal regions by the Sylvian fissure within which runs the middle cerebral artery. The amygdala and hippocampus were included within the temporal lobe, and midbrain structures were excluded (Fig. $1 B$ ). The posterior temporal lobe was delineated by a line extending from the anteriormost tip of the contralateral cerebral peduncle to the anteromedialmost tip of the cerebellum (the dashed line in Fig. 1B).

Above the level of the mammillary bodies, the posterior border of the frontal lobe was delineated by a horizontal line that extended from the anteromedial-most aspect of the Sylvian fissure to midline (Fig. 1C). The medial borders of the temporal lobe were the Sylvian fissure and 


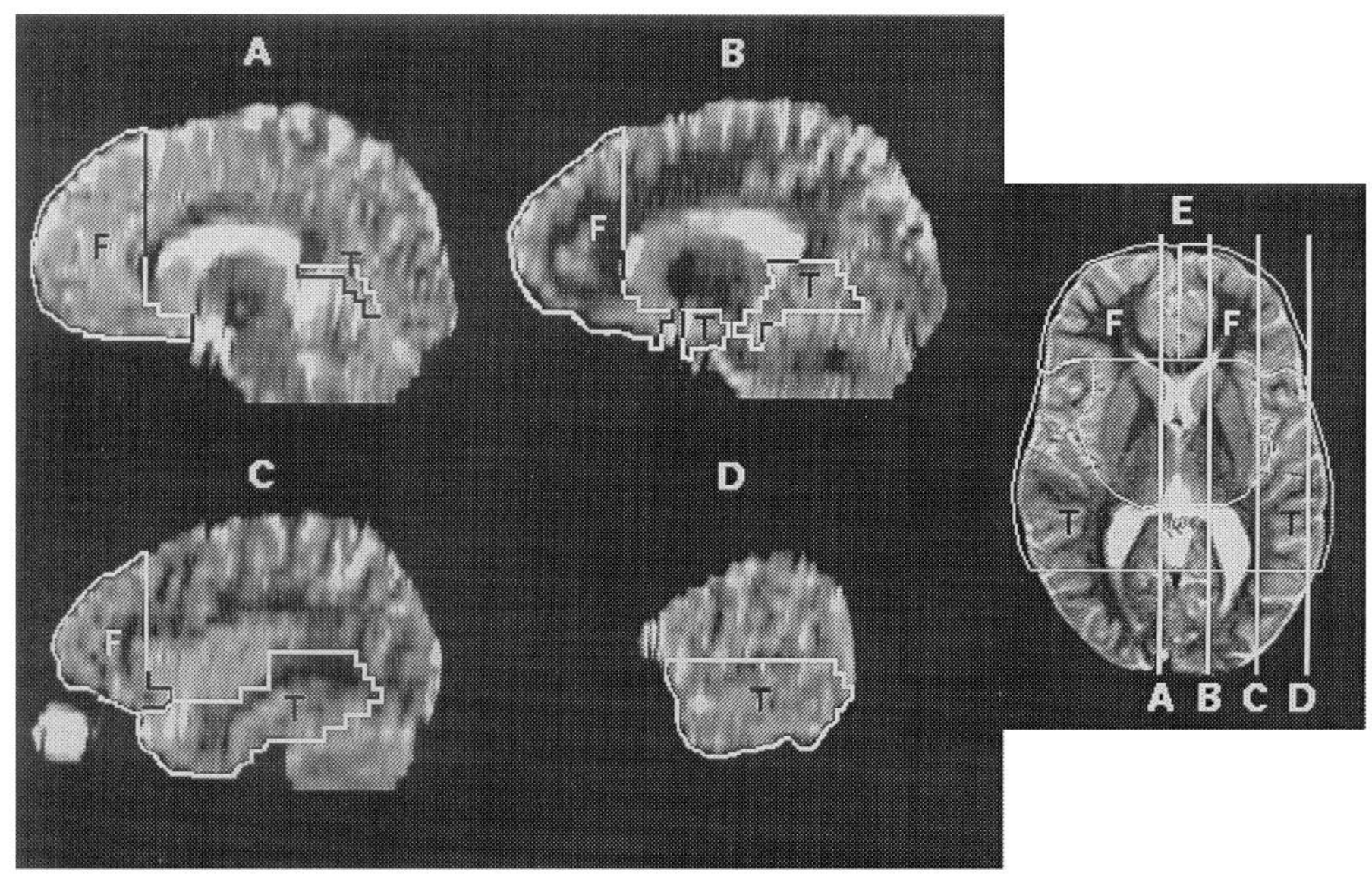

Figure 2. The frontal and temporal brain regions as they appear on a $5 \mathrm{~mm} \mathrm{~T} 2$ image resliced into the sagittal plane. The locations of these sagittal slices $(A-D)$ are shown in the axial plane as grids spanning the anterior to posterior extent of the brain in $E$. $F$, frontal region; $T$, temporal region.

structures of the diencephalon (Fig. $1 C, D$ ). A horizontal line, extending from the posteriormost tip of the posterior fossa to the lateral cortical perimeter, delineated the posterior temporal lobe (Fig. 1C). The posterior border for the remaining superior slices containing frontal lobe was delineated in the slice immediately inferior to the crossing of the splenium of the corpus callosum (Fig. 1D). A line defined by the anteriormost aspect of the caudate was drawn from midline to the Sylvian fissure. This slice was also the most superior location at which temporal lobe borders were drawn.

Figure 2 depicts sagittal views of the frontal and temporal brain regions. These images were obtained by projecting the frontal and temporal brain volumes derived from drawings made in the axial plane onto the same subject's MRI resliced into the sagittal plane. Loss of image resolution occurred with reslicing of the $5 \mathrm{~mm}$ image, making it difficult to discern which neuroanatomical structures were located within the frontal and temporal regions. Figure 3 presents an image acquired in slices of $1 \mathrm{~mm}$ thickness (spoiled GRASS pulse sequence, flip angle $=35, \mathrm{TR}=35$, $\mathrm{TE}=6$, field of view $=24$, nex $=1$ ) for the subject whose brain was presented in Figure 2. By comparing the $5 \mathrm{~mm}$ image (Fig. 2) to the 1 mm image (Fig. 3), it can be seen that the frontal region is primarily prefrontal and that although most of the temporal lobe is encompassed, this region may also include some frontal or occipital cortex.

Volumetric brain analysis technique. Once regions were delineated, the program calculated regional volumes based on brain slice data from which CSF was excluded. Our segmentation approach (Kohn et al., 1991) uses proton density and T2 as independent properties that influence image values. With a multiecho acquisition protocol, these properties can be isolated as multiple, spatially registered, independent features of the tissue. A population distribution of pixel values in the images was generated for each feature (e.g., brain and CSF), and discrete clusters were identified that represent the tissue classes in a "feature space" plot. Even in cases where shading artifacts distort cluster shape, the ability to segment CSF and brain is preserved, as shown in phantom studies (Kohn et al., 1991).
Reliability of regional volumetric measurements. A sample of 10 randomly selected scans was analyzed by two raters (B.I.T. and P.E.C.). Correlations of the left and right frontal and temporal brain volumes for the two raters ranged from 0.959 to 0.984 . One of these investigators (P.E.C.) then completed the analysis on the remaining scans.

Dependent measures. Left and right frontal and temporal brain volumes were calculated for each subject. These served as the main dependent measures. In addition, whole-brain and CSF volumes were available from prior studies on these subjects (Gur et al., 1991). Using these values, the brain was subdivided into three regional proportions: $F=$ total frontal volume/cranial volume; $T=$ total temporal volume/ cranial volume; $X=$ whole-brain volume - (total frontal volume + total temporal volume)/cranial volume. These proportions were used to examine age and sex differences in cranium-corrected regional analyses.

Statistics. A repeated-measures analysis of variance (ANOVA; SAS general linear model procedure) was performed with the left and right temporal and frontal volumes as dependent measures. Region (frontal vs temporal) and hemisphere (left vs right) were repeated measures. Sex (men vs women) and age (18-40 vs 41-80 years) were the classifying (between-group) variables. The same ANOVA design was also applied to the cranial volume corrected ratios.

\section{Results}

\section{Analysis of volume data}

Table 1 provides means of the left and right temporal and frontal volumes. An age $\times$ sex $\times$ hemisphere $\times$ region interaction $[F(1,126)=3.97, p<0.05]$ indicated that age-related reductions in brain volume were sexually dimorphic, lateralized, and region specific. Therefore, age $\times \operatorname{sex} \times$ hemisphere ANOVAs were performed separately for the frontal and temporal volumes. 


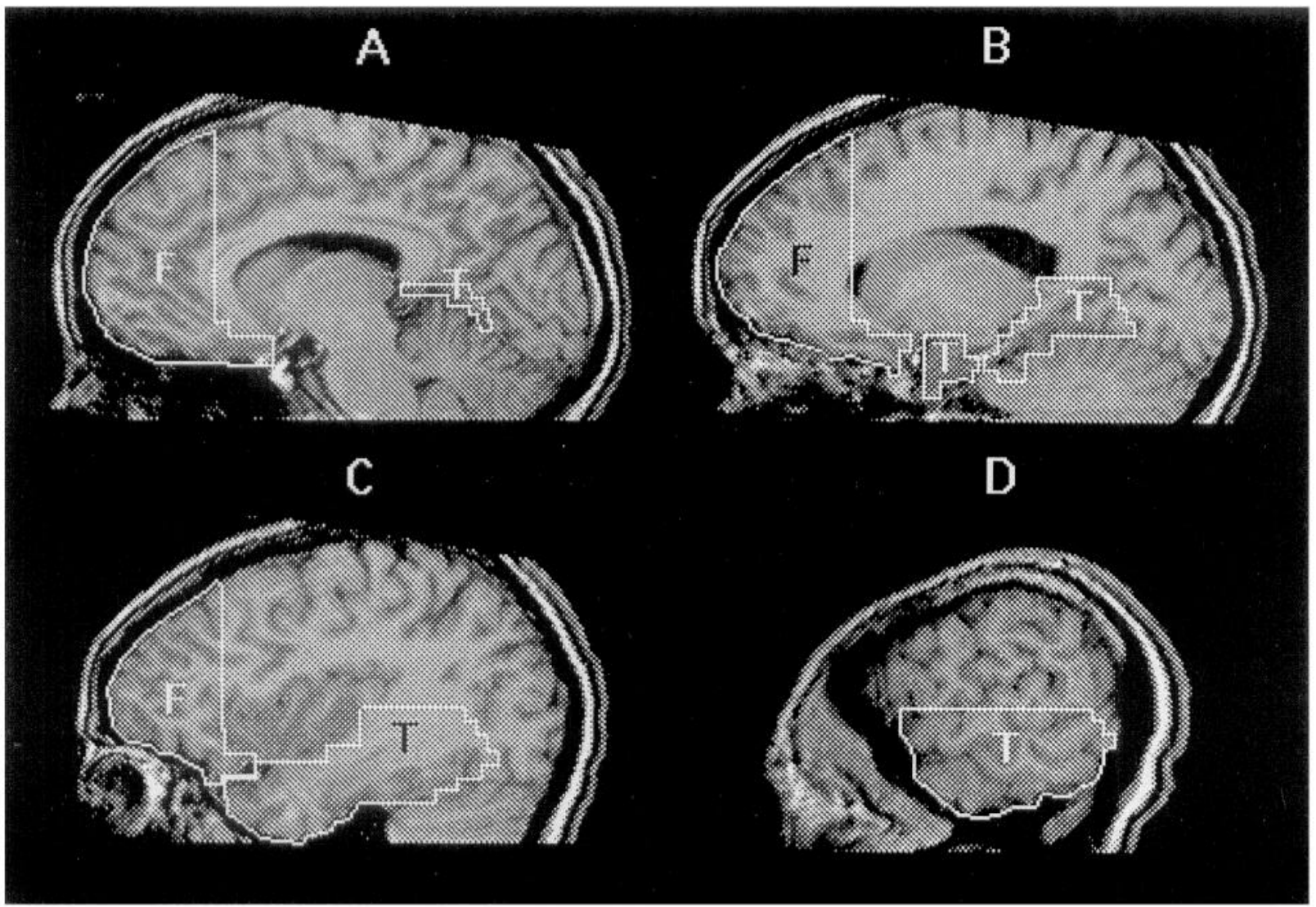

Figure 3. A view of the brain seen in Figure 2 as it appears in a $1 \mathrm{~mm}$ spoiled GRASS image. $A-D$ depict the same sagittal planes as seen in Figure $2 A-D$. The frontal and temporal regions depicted in Figure 2 have been redrawn onto Figure 3. (Slight variations in the appearance of the frontal and temporal regions in Fig. 3 are due to differences in pixel size between the $5 \mathrm{~mm}$ and $1 \mathrm{~mm}$ images.) $F$, frontal region; $T$, temporal region.

In the frontal lobe, a main effect of age $[F(1,126)=9.06, p$ $=0.0032]$ indicated that older subjects had lower volumes than younger subjects. A main effect of $\operatorname{sex}[F(1,126)=6.85, p=$ 0.0099 ] showed that men had larger frontal volumes than women. The effect of hemisphere was also significant $[F(1,126)=$ $46.5, p=0.0001]$ with right frontal volume greater than the left for both sexes. An age $\times$ sex interaction $] F(1,126)=11.23, p$ $=0.0011 \mathrm{l}$ reflected significant differences in frontal brain volume between the two age groups in men $[F(1,68)=18.86, p=$ $0.0001]$ but not women (Fig. 4). Total frontal volume in younger men was $16 \%$ larger than in older men, whereas in women this volume was virtually the same in the two age groups. A threeway age $\times$ sex $\times$ hemisphere interaction $[F(1,126)=3.92, p=$ 0.0499 ] indicated that age affected the right and left hemispheres differently in men and women. In men, the volumetric decrease with age in the right frontal lobe was approximately $1 \mathrm{ml}$ greater than in the left. In women, the difference in asymmetry was attributable to a $2 \mathrm{ml}$ increase in the right frontal volume in the older group (Table 1). Right frontal lobe volume was between 2.1 and $3.2 \%$ greater than the left in younger men, older men, and younger women, but was almost $5 \%$ greater than the left in older women. Thus, changes in laterality with age were significant only in women $[F(1,58)=4.03, p=0.0493]$.

In the temporal lobe, $\operatorname{sex}[F(1,126)=21.42, p=0.0001]$ and hemisphere $[F(1,126)=4.93, p=0.0282]$ effects were similar to those in the frontal lobe, with men having larger volumes than women and right volume being greater than left. The age effect was not significant, indicating that temporal lobe was not as susceptible as the frontal lobe to the effects of aging. However, as in the total frontal volume, total temporal volume was lower in older men but not women [age $\times \operatorname{sex}: F(1,126)=4.72, p=$ $0.0318]$. In addition, the rightward asymmetry in temporal volume was greater in men than in women across age groups [sex $\times$ hemisphere: $F(1,126)=4.83, p=0.0299$ ]. Lower left relative to right temporal volume of older men enhanced this effect with age (Table 1, Fig. 4).

\section{Analysis of cranial volume corrected data}

Cranial volume (whole-brain volume + CSF volume) did not correlate with age, confirming the anticipated lack of secular effects in head size ( $r=0.014$, NS). However, cranial volume was highly correlated with frontal $(r=0.769)$ and temporal $(r$ $=0.719$ ) volumes $(p$ values $<0.001)$. For this reason, it was worthwhile to investigate how regional brain volumes differed between the age groups when expressed as proportions of cranial volume ( $F, T$, and $X$ ratios defined in Materials and Methods). Values for the age and sex groups are shown in Figure 5.

For the $F$ proportion, the main effects of age group $[F(1,126)$ $=37.56, p=0.0001]$, with higher values in younger subjects, and hemisphere $[F(1,126)=49.67, p=0.0001]$, with higher right side values, as well as the age $\times \operatorname{sex}[F(1,126)=7.19, p$ $=0.0083]$, and trend for age $\times$ sex $\times$ hemisphere interaction $[F(1,126)=3.53, p=0.0626]$, paralleled those seen with the raw measures. However, the sex difference seen in raw volumes, 
Figure 4. Raw means and standard errors for total frontal (top left) and temporal (top right) volumes $(\mathrm{ml})$ as a function of scx and agc. Decreases in both regions were significant for men only. Mean frontal and temporal laterality scores (left volume - right volume) as a function of sex and age are plotted in the bottom graphs. Laterality bars extending below zero indicate a right $>$ left asymmetry $(R>L)$. Men lost slightly more volume in the right frontal and left temporal with age, whereas older women had an increased volume in the right frontal region.
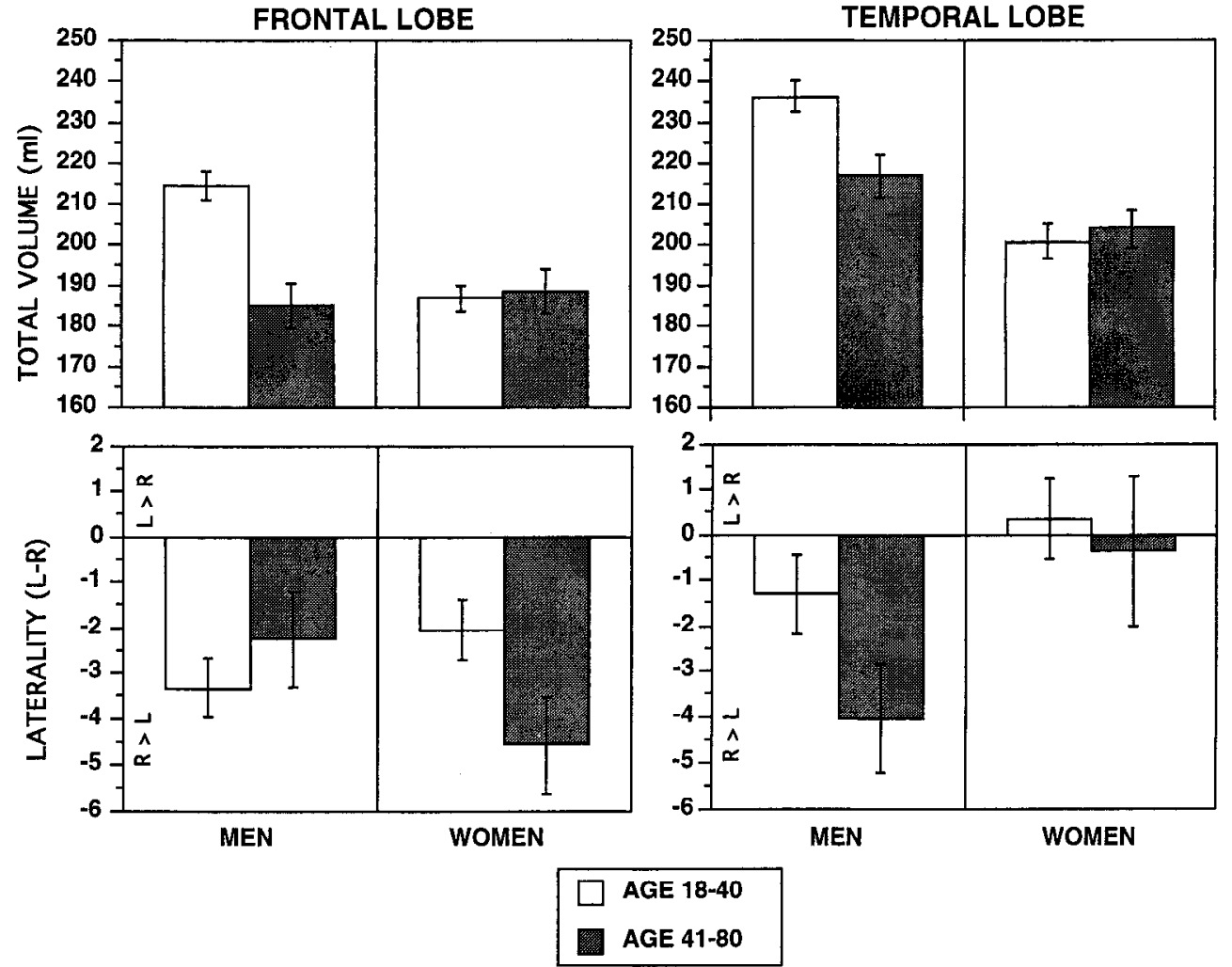

with men having larger frontal lobes, were reversed for the $F$ proportion [sex; $F(1,126)=8.63, p=0.0039]$. This indicated that while frontal lobes had lower volume in women, they occupied a larger proportion of the cranial volumes in women than in men. The latter effect, however, was enhanced by the lower values in older men. Figure 5 shows that $F$ was the same for younger men and women, but was reduced in older men compared to older women $[F(1,32)=11.33, p=0.002]$.

For the $T$ proportion, the main effect of sex, and the age $\times$ sex and sex $\times$ hemisphere interactions were diminished compared to the analysis of raw values, and a significant main effect of age emerged $[F(1,126)=8.42, p=0.0044]$. $T$ was lower in the older men $[F(1,68)=7.64, p=0.0073]$, but not in older women. The differences between the age groups remained more pervasive in the frontal proportion than in the temporal proportion.

For the $X$ proportion, the main effect of age group was significant, indicating a decreased proportion in the older subjects across sex groups $[F(1,126)=26.73, p=0.0001]$. Of the three regional proportions, $X$ showed the most highly significant age- related decrease in women $[F(1,58)=17.69, p=0.0001]$ (Fig. 5).

\section{Discussion}

Previous studics of scx differences in aging concluded that ncuromorphologic changes occurred in one sex faster or earlier than in the other (Hatazawa et al., 1982; Hubbard and Anderson, 1983; Laffey et al., 1984; Takeda and Matsuzawa, 1985; Grant et al., 1987; Condon et al., 1988; Allen et al., 1991; Gur et al., 1991). Results from our analysis of the frontal and temporal lobes are consistent with previous reports suggesting that the effects of age are more pronounced for men. In the present study, age $\times$ sex effects were most marked in the frontal lobe. This is consistent with findings that anterior regions of the corpus callosum decrease in width at an earlier age in men than in women (Cowell et al., 1992). The volume of temporal lobe was also more reduced in older men than women, but this was not true in the remaining portion of the brain where older women also showed reduced volume. This suggests that regions more sensitive to the effects of aging in women than the frontal and

Table 1. Mean $\pm \mathrm{SE}$ frontal and temporal lobe volumes as a function of age, sex, and hemisphere

\begin{tabular}{lcrrrr} 
& \multicolumn{1}{l}{ Men } & & Women & \\
\cline { 2 - 3 } & $\begin{array}{l}\text { Younger } \\
(n=53)\end{array}$ & $\begin{array}{l}\text { Older } \\
(n=17)\end{array}$ & & $\begin{array}{l}\text { Younger } \\
(n=43)\end{array}$ & \multicolumn{1}{l}{$\begin{array}{l}\text { Older } \\
(n=17)\end{array}$} \\
\hline Age & $25.64 \pm 0.77$ & $63.12 \pm 2.74$ & & $24.47 \pm 0.84$ & $60.41 \pm 2.72$ \\
Left frontal & $105.57 \pm 1.74$ & $91.28 \pm 3.02$ & & $92.29 \pm 1.68$ & $91.84 \pm 2.77$ \\
Right frontal & $108.89 \pm 1.74$ & $93.54 \pm 2.67$ & & $94.36 \pm 1.68$ & $96.40 \pm 2.80$ \\
Left temporal & $117.31 \pm 1.84$ & $106.29 \pm 2.30$ & & $100.39 \pm 2.23$ & $101.71 \pm 2.53$ \\
Right temporal & $118.64 \pm 2.00$ & $110.33 \pm 2.91$ & & $100.04 \pm 2.20$ & $102.08 \pm 2.52$
\end{tabular}




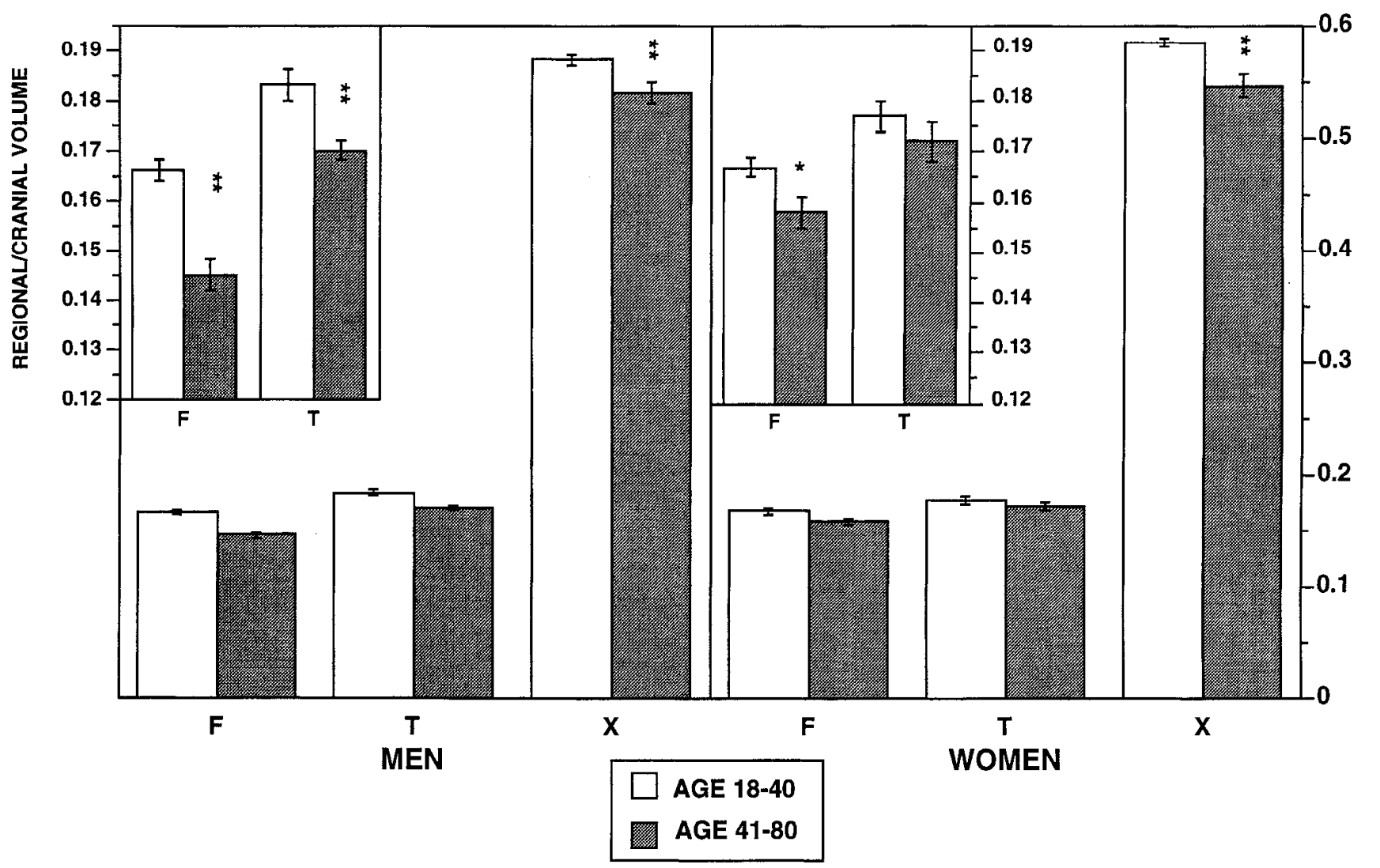

Figure 5. Proportions of regional frontal $(F)$, temporal $(T)$, and remaining $(X)$ brain volumes to cranial volume as a function of sex and age. Frontal and temporal proportions are displayed in the same scale as the $X$ proportion (bottom) and in a smaller scale in the top left corner of each plot. Age-related decreases in frontal and temporal proportions were greater in men than in women. Older subjects of both sexes had lower volumes in the $X$ region. (*, age $p<0.05 ;{ }^{* *}$, age $p<0.01$.)

temporal regions examined in this study may be located within the primary motor cortex, parietal lobe, occipital lobe, or subcortex (e.g., thalamus, basal ganglia).

Our regional analysis also suggested that age-related changes in cerebral asymmetry may be sexually dimorphic. The laterality effects were not as robust as the interactive effects of age and sex on total frontal and temporal volume, yet are noteworthy in light of similar phenomena reported in rodents. Diamond et al. (1983) showed that adult male rats had a right $>$ left asymmetry in cortical thickness that became weaker with advanced age. In contrast, cortical thickness in female rats was slightly greater in the left than the right hemisphere, a pattern that also changed with age.

Studies of cerebral blood flow and metabolism in humans support frontal lobe sensitivity to the effects of aging (Kuhl et al., 1982; Duara et al., 1984; Pantano et al., 1984; Shaw et al., 1984; Rodriguez et al., 1988; Leenders et al., 1990; Martin et al., 1991; Azari et al., 1992b). Regions within the temporal lobe were less frequently implicated (Pantano et al., 1984; Shaw et al., 1984; Martin et al., 1991). With regard to sex, differences in blood flow between men and women have been shown to decrease with age (Shaw et al., 1984; Gur et al., 1987; Gur and Gur, 1990). Age-related changes were also lateralized, especially in frontal lobe structures (Duara et al., 1984; Shaw et al., 1984; Rodriguez et al., 1988; Martin et al., 1991). One study reported a decrease in cerebral blood flow of left frontal regions in men but not in women (Rodriguez et al., 1988). These studies show that brain function, as well as brain structure, ages in a regionspecific, sexually dimorphic, and lateralized fashion.

The study of aging at the cellular level in humans suggests cytoarchitectural components that may contribute to decreases in regional volume. Age-related changes in the frontal lobe include decreased cortical thickness and shrinkage of large neurons (Anderson et al., 1983; Terry et al., 1987), cell loss (Anderson et al., 1983), and decreased density of synapses in cortical layer III (Huttenlocher, 1979). In the temporal lobe, decreased cortical thickness and neuronal shrinkage were present, but less pronounced than in the frontal lobe (Terry et al., 1987). Other age-related changes in the temporal lobe included cell loss (Brody, 1955) and decrease in total dendritic length of supragranular pyramidal cells in left Wernicke's area (Scheibel and Jacobs, 1991). Unfortunately, most neuroanatomical studies of aging in humans report data averaged across sex and hemisphere.

The study of neuroendocrinology in animals provides strong support for the present finding that sex differences in human brain structure vary as a function of region, age, and hemisphere. The presence of gonadal steroids has been associated with neural growth, and their removal with retarded development and atrophy (Nordeen et al., 1985; Fitch et al., 1990a,b, 1991b; Gould et al., 1990; Segarra and McEwen, 1991). In addition, estrogen has been shown to have inhibitory effects on neural development (Diamond et al., 1981; Fitch et al., 1991a; Mack et al., 1993). Androgen and estrogen receptor populations are distributed in varying concentrations throughout the developing brain (Pom- 
erantz et al., 1985; MacLusky et al., 1986), thereby providing some basis for the regionality of later sex differences. Furthermore, the topographical distribution, binding capacity, and associated enzyme levels of these receptor systems have been shown to vary as a function of age (MacLusky et al., 1979; Sholl et al., 1989; Brown et al., 1990). Decreased regional brain volumes in older humans may also be attributed to such factors as fluctuations in hormone levels coupled with changes in the characteristics of receptors. Hormone receptor populations have also been shown to be lateralized (Sandhu et al., 1986; Sholl and Kim, 1990). Sholl and Kim (1990) found that androgen receptor levels in male fetal monkeys were higher in the right than left frontal lobe and in the left than right temporal lobe. These are the same locations that were most sensitive to the effects of aging in men in the present study. Sholl and Kim's (1990) report, in conjunction with our findings, suggests that brain regions with high androgen receptor populations early in development may be more susceptible to aging effects later in life.

Behavioral correlates of age by sex interactions in neuroanatomy merit examination. In nonhuman primates, sex differences in memory performance emerged at discrete developmental periods and were correlated with dimorphisms in the development of frontal and temporal cortices (Goldman-Rakic et al., 1974; Clark and Goldman-Rakic, 1989; Bachevalier et al., 1990). While human brain structure has repeatedly been shown to be sensitive to the effects of age and sex, little is known about the interactive effects of these variables on regional neuroanatomy and behavior across the human life span. Our findings provide evidence that sex differences in human brain structure are not fixed, but continue to evolve throughout adulthood. Furthermore, dimorphisms in aging are region specific and may have their origins in early neuroendocrinological development.

\section{References}

Allen L, Gorski R (1990) Sex differences in the bed nucleus of the stria terminalis in the human brain. J Comp Neurol 302:697-706.

Allen L, Gorski R (1991) Sexual dimorphism of the anterior commissure and massa intermedia of the human brain. J Comp Neurol 312:97-104.

Allen L, Hines M, Shryne J, Gorski R (1989) Sexually dimorphic cell groups in the human brain. J Neurosci 9:497-506.

Allen L, Richey M, Chai Y, Gorski R (1991) Sex differences in the cerebral cortex and the callosum of the living human being. J Neurosci 11:933-942.

Anderson J, Hubbard B, Coghill G, Slidders W (1983) The effect of advanced old age on the neurone content of the cerebral cortex. J Neurol Sci 58:233-246.

Azari N, Rapoport S, Grady C, DeCarli C, Haxby J, Schapiro M, Horwitz B (1992a) Gender differences in correlations of cerebral glucose metabolic rates in young normal adults. Brain Res 574:198-208.

Azari N, Rapoport S, Salerno J, Grady C, Gonzalez-Aviles A, Schapiro M, Horwitz B (1992b) Interregional correlations of resting cerebral glucose metabolism in old and young women. Brain Res 589:279290.

Bachevalier J, Brickson M, Hagger C, Mishkin M (1990) Age and sex differences in the effects of selective temporal lobe lesion on the formation of visual discrimination habits in rhesus monkeys (Macaca mulatta). Behav Neurosci 104:885-899.

Brody H (1955) Organization of the cerebral cortex. III. A study of aging in the human cerebral cortex. J Comp Neurol 102:511-556.

Brown T, MacLusky N, Shanabrough M, Naftolin F (1990) Comparison of age- and sex-related changes in cell nuclear estrogen-binding capacity and progestin receptor induction in the rat brain. Endocrinology 126:2965-2972.

Buell S, Coleman P (1979) Dendritic growth in the aged human brain and failure of growth in senile dementia. Science 206:854-906.

Clark A, Goldman-Rakic P (1989) Gonadal hormones influence the emergence of cortical function in nonhuman primates. Behav Neurosci 103:1287-1295.

Clarke S, Kraftsik R, Van der Loos H, Innocenti G (1989) Forms and measures of adult and developing human corpus callosum: is there sexual dimorphism. J Comp Neurol 280:213-230.

Coffey C, Wilkinson W, Parashos I, Soady S, Sullivan R, Patterson L, Figiel G, Webb M, Spritzer C, Djang W (1992) Quantitative cerebral anatomy of the aging human brain: a cross-sectional study using magnetic resonance imaging. Neurology 42:527-536.

Condon B, Grant R, Hadley D, Lawrence A (1988) Brain and intracranial cavity volumes: in vivo determination by MRI. Acta Neurol Scand 78:387-393.

Cowell P, Allen L, Zalatimo N, Denenberg V (1992) A developmental study of sex by age interactions in human corpus callosum. Dev Brain Res 66:187-192.

Davis P, Wright E (1977) A new method for measuring cranial cavity volume and its application to the assessment of cerebral atrophy at autopsy. Neuropathol Appl Neurobiol 3:341-358.

deLacoste-Utamsing $M$, Holloway R (1982) Sexual dimorphism in the human corpus callosum. Science 216:1431-1432.

de Leon M, George A, Ferris S, Christman D, Fowler J, Gentes C, Brodie J, Reisberg B, Wolf A (1984) Positron emission tomography and computed tomography assessments of the aging human brain. $J$ Comput Assist Tomogr 8:88-94.

Demeter S, Ringo J, Doty R (1988) Morphometric analysis of the human corpus callosum and anterior commissure. Hum Neurobiol $6: 219-226$

Denenberg V, Cowell P, Kertesz A (1991) A factor analysis of the human's corpus callosum. Brain Res 548:126-132.

Diamond M, Johnson R, Ingham C (1975) Morphologic changes in the young, adult and aging rat cerebral cortex, hippocampus and diencephalon. Behav Biol 14:163-174.

Diamond M, Dowling $G$, Johnson $R$ (1981) Morphologic cerebral cortical asymmetry in male and female rats. Exp Neurol 71:261-268.

Diamond M, Johnson R, Young D, Singh S (1983) Age-related morphologic differences in the rat cerebral cortex and hippocampus: malefemale; right-left. Exp Neurol 81:1-13

Duara R, Grady C, Haxby J, Ingvar D, Sokoloff L, Margolin R, Manning R, Cutler N, Rapoport S (1984) Human brain glucose utilization and cognitive function in relation to age. Ann Neurol 16:702-713.

Fernandez-Ruiz. J, De Miguel R, Hernandez M, Cebeira M, Ramos J (1992) Comparisons between brain dopaminergic neurons of juvenile and aged rats: sex related differences. Mech Ageing Dev 63:45-55.

Fitch R, Berrebi A, Cowell P, Schrott L, Denenberg V (1990a) Corpus callosum: effects of neonatal hormones on sexual dimorphism in the rat. Brain Res 515:111-116.

Fitch R, Berrebi A, Cowell P, Schrott L, Denenberg V (1990b) Curpus callosum: neonatal hormones and development. Paper presented at the International Society for Developmental Psychobiology annual meeting, Cambridge, UK

Fitch R, Cowell P, Schrott L, Denenberg V (1991a) Corpus callosum: ovarian hormones and feminization. Brain Res 542:313-317.

Fitch R, Cowell P, Schrott L, Denenberg V (1991b) Corpus callosum demasculinization via perinatal anti-androgen. Int $\mathrm{J}$ Dev Neurosci 9:35-38.

Goldman-Rakic P, Crawford H, Stokes L, Rosvold H (1974) Sexdependent behavioral effects of cerebral cortical lesions in the developing rhesus monkey. Science 186:540-542.

Gould E, Woolley C, Frankfurt M, McEwen B (1990) Gonadal steroids regulate dendritic spine density in hippocampal pyramidal cells in adulthood. J Neurosci 10:1286-1291.

Grant R, Condon B, Lawrence A, Hadley D, Patterson J, Bone I, Teasdale $G$ (1987) Human cranial CSF volumes measured by MRI: sex and age influences. Magn Reson Imaging 5:465-468.

Gur RC, Gur RE, Obrist W, Hungerbuhler J, Younkin D, Rosen A, Skolnick B, Reivich M (1982) Sex and handedness differences in cerebral blood flow during rest and cognitive activity. Science 217: 659-660.

Gur RC, Gur RE, Obrist W, Skolnick B, Reivich M (1987) Age and regional cerebral blood flow at rest and during cognitive activation. Arch Gen Psychiatry 44:617-621.

Gur RC, Mozley PD, Resnick S, Gottlieb G, Kohn M, Zimmerman R, Herman G, Atlas S, Grossman R, Berretta D, Erwin R, Gur RE (1991) Gender differences in age effect on brain atrophy measured by magnetic resonance imaging. Proc Natl Acad Sci USA 88:28452849 . 
Gur RE, Gur RC (1990) Gender differences in regional cerebral blood flow. Schizophr Bull 16:247-254.

Hatazawa J, Masatoshi I, Harutsugu Y, Matsuzawa T (1982) Sex differences in brain atrophy during aging: a quantitative study with computed tomography. J Am Geriatr Soc 30:235-239.

Hubbard B, Anderson J (1983) Sex differences in brain related atrophy. Lancet 8339:1447-1448.

Huttenlocher P (1979) Synaptic changes in human frontal cortexdevelopmental changes and effects of aging. Brain Res 163:195-205.

Jack C, Petersen R, O'Brien P, Tangalos E (1992) MR-based hippocampal volumetry in the diagnosis of Alzheimer's disease. Neurology 42:183-188.

Jernigan T, Press G, Hesselink J (1990) Methods for measuring brain morphologic features on magnetic resonance images. Arch Neurol 47: $27-32$.

Kertesz A, Polk M, Black S, Howell J (1990) Sex, handedness, and the morphometry of cerebral asymmetries on magnetic resonance imaging. Brain Res 530:40-48.

Kimura D (1986) Sex differences in cerebral organization for speech and praxic functions. Can J Psychol 37:19-35.

Kimura D (1987) Are men's and women's brains really different? Can Psychol 28:133-147.

Kohn M, Tanna N, Herman G, Resnick S, Mozley PD, Gur RE, Alavi A, Zimmerman R, Gur RC (1991) Analysis of brain and cerebrospinal fluid volumes with MR imaging. Radiology 178:115-122.

Kuhl D, Metter E, Riege W, Phelps M (1982) Effects of human aging on patterns of local cerebral glucose utilization determined by the fluorodeoxyglucose method. J Cereb Blood Flow Metab 2:163-171.

Laffey P, Peyster R, Nathan R, Haskin M, McGinley J (1984) Computed tomography and aging: results in a normal clderly population. Neuroradiology 26:273-278.

Leenders K, Perani D, Lammertsma A, Heather J, Buckingham P, Healy M, Gibbs J, Wise R, Hatazawa J, Herold S, Beaney R, Brooks D, Spinks T, Rhodes C, Frackowiak R, Jones T (1990) Cerebral blood flow, blood volume and oxygen utilization. Brain 113:27-47.

Mack C, Fitch RH, Cowell P, Schrott L, Denenberg V (1993) Ovarian estrogen acts to feminize the female rat's corpus callosum. Dev Brain Res 71:115-119.

MacLusky N, Lieberburg I, McEwen B (1979) The development of estrogen receptor systems in the rat brain: perinatal development. Brain Res 178:143-160

MacLusky N, Naftolin F, Goldman-Rakic P (1986) Estrogen formation in the cerebral cortex of the developing rhesus monkey. Proc Natl Acad Sci USA 83:513-516.

Martin A, Friston K, Colebatch J, Frackowiak R (1991) Decreases in regional cerebral blood flow with normal aging. J Cereb Blood Flow Melab 11:684-689.

Miller A, Alston R, Corsellis J (1980) Variation with age in the volumes of grey and white matter in the cerebral hemispheres of man: measurements with an image analyser. Neuropathol Appl Neurobiol $6: 119-132$

Naritomi H, Meyer J, Sakai F, Yamaguchi F, Shaw T (1979) Effects of advancing age on regional cerebral blood flow. Arch Neurol 36: $410-416$

Nordeen F, Nordeen K, Sengelaub, Arnold A (1985) Androgens prevent normally occurring cell death in a sexually dimorphic spinal nucleus. Science 229:671-673.

Pantano P, Baron J, Lebrun-Grandie P, Duquesnoy N, Bousser M, Comar D (1984) Regional cerebral blood flow and oxygen consumption in human aging. Stroke 15:635-641.
Pfefferbaum A, Zatz L, Jernigan T (1986) Computer-interactive method for quantifying fluid and tissue in brain CT scans: effects of aging. J Comp Assist Tomogr 10:571-578.

Pomerantz S, Fox T, Sholl S, Vito C, Goy R (1985) Androgen and estrogen receptors in fetal rhesus monkey brain and anterior pituitary. Endocrinology 116:83-89.

Rackzowski C, Kalat J, Nebes R (1974) Reliability and validity of some handedness questionnaire items. Neuropsychologia 12:43-48.

Rodriguez G, Warkentin S, Risberg J, Rosadini G (1988) Sex differences in regional blood flow. J Cereb Blood Flow Metab 8:783-789.

Sandhu S, Cook P, Diamond M (1986) Rat cerebral cortical estrogen receptors: male-female, right-left. Exp Neurol 92:186-196.

Saykin A, Gur RC, Gur RE, Mozley PD, Mozley L, Resnick S, Kester B, Stafiniak P (1991) Neuropsychological function in schizophrenia: selective impairment in memory and learning. Arch Gen Psychiatry 48:618-624.

Scheibel A, Jacobs B (1991) Age-related changes in Wernicke's area: a quantitative dendritic analysis. Soc Neurosci Abstr 17:1507.

Segarra A, McEwen B (1991) Estrogen increases spine density in ventromedial hypothalamic neurons in peripubertal rats. Neuroendocrinology 54:365-372.

Shaw T, Mortel K, Meyer J, Rogers R, Hardenberg J, Cutaia M (1984) Cerebral blood flow changes in benign aging and cerebrovascular disease. Neurology 34:855-862.

Sholl S, Kim K (1990) Androgen receptors are differentially distributed between right and left cerebral hemispheres of the fetal rhesus monkey. Brain Res 516:122-126.

Sholl S, Goy R, Kim K (1989) 5-Alpha-reductase, aromatase and androgen receptor levels in the monkey brain during fetal development. Endocrinology 124:627-634.

Shtasel D, Gur RE, Mozley PD, Richards J, Taleff M, Heimberg C, Gallacher F, Gur RC (1991) Volunteers for biomedical research: recruitment and screening of normal controls. Arch Gen Psychiatry 48:1022-1025.

Spitzer R, Williams J, Gibbon M (1986) Structured clinical interview for DSM-III-R. New York: New York Psychiatric Institute.

Takeda S, Matsuzawa T (1985) Age-related brain atrophy: a study with computed tomography. J Gerontol 40:159-163.

Terry R, DeTeresa R, Hansen L (1987) Neocortical cell counts in normal human adult aging. Ann Neurol 21:530-539.

Toran-Allerand CD (1978) Gonadal hormones and brain development: cellular aspects of sexual differentiation. Am Zool 18:553-565.

Witelson S (1989) Hand and sex differences in the isthmus and genu of the human corpus callosum. Brain 112:799-835.

Witelson S (1991) Sexual differentiation of the human temporo-parietal region for functional asymmetry: neuroanatomical evidence. Psychoneuroendocrinology 16:131-153.

Wood F, Flowers D, Naylor C (1990) Cerebral laterality in functional neuroimaging. In: Cerebral laterality theory and research: the Toledo symposium (Kitterle F, ed), pp 103-116. Hillsdale, NJ: Erlbaum.

Yakovlev P, Lecours A (1967) The myelination cycles of regional maturation of the brain. In: Regional development of the brain in early life (Minkowski A, ed), pp 3-70. Oxford: Blackwell.

Zaidel E, Clarke J, Suyenobou B (1990) Hemispheric independence: a paradigm case for cognitive neuroscience. In: Neurobiological foundations of higher cognitive function (Scheibel A, Wechsler A, eds), pp 297-355. New York: Guilford. 